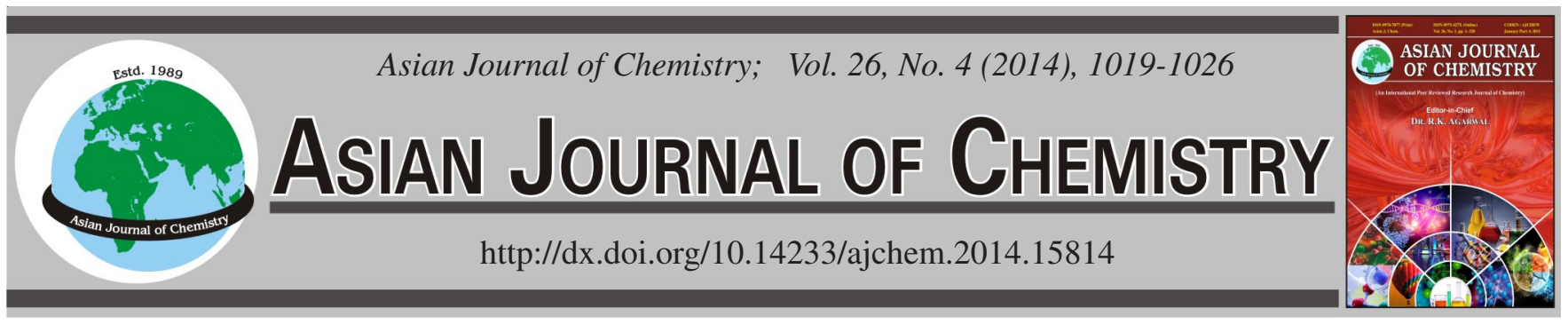

\title{
Theoretical Study on Synthesis of Sylvestrene by Cyclodimerization of Isoprene: Asynchronous Concerted Mechanism of Diels-Alder Reaction
}

Chuan-Ming Wang ${ }^{1,2,3,}$, Yi-Lei $_{\text {Chen }}^{3, \dagger}, Z_{\text {Hi-Hua Liu }}^{1}$, Yong-Kuan Chen ${ }^{1}$, Jing-Mei Han ${ }^{1}$, Ming-Ming MiaO ${ }^{1}$ and Huai CaO ${ }^{3, *}$

${ }^{1}$ Key Lab of Tobacco Chemistry of Yunnan, Yunnan Academy of Tobacco Science, Kunming 650000, P.R. China

${ }^{2}$ University Key Laboratory of Crop High Quality, Effective Cultivation and Safety Control in Yunnan Province, Honghe University, Mengzi 661100, P.R. China

${ }^{3}$ Modern Biological Research Center, Yunnan University, Kunming 650091, P.R. China

*Corresponding author: Fax: +86 871 65036373; Tel: +86 871 65033496; E-mail: caohuai@ynu.edu.cn

$\dagger$ These authors contributed equally to these work.

\begin{abstract}
Computations on Diels-Alder cycloadditions of sylvestrene from isoprene monomers reveal asynchronous concerted transition structures. The hardness profiles along the intrinsic reaction coordinate present a minimum shift with respect to the transition states. The densities of HOMO and LUMO can explain why the first new bond is formed at the end of double bonds of two isoprenes. All adducts are stereoisomers with similar energies. The asynchronous degree of the endo addition reaction involved in cis-isoprene as dienophile is greater and its potential energy barrier, $10 \mathrm{~kJ} / \mathrm{mol}$, is lower than that of any other reaction pathways.
\end{abstract}

Keywords: Diels-alder reaction, Isoprene, Asynchronous concerted reaction, Hardness, Sylvestrene.

\section{INTRODUCTION}

Isoprene is the basic structural unit of some important natural oligomers such as the terpenes and steroids and polymers such as caoutchouc (cis-1,4) and Gutta-Percha (trans-1,4). It is also the major component of the unsaturated gaseous hydrocarbons present in tobacco smoke. It had been proposed that the terpene components of tobacco (such as solanesol) can decompose into isoprene ${ }^{1}$ and pyrosynthesize into larger polycyclic aromatic hydrocarbons $(\mathrm{PAHs})^{2}$, including benzo $[a]$ pyrene which is a widespread environmental pollutant and carcinogen. Dimerization of isoprene via Diels-Alder reaction, yields mixtures of cyclic monoterpenes in which sylvestrene (1-methyl-3-isopropenyl-cyclohexene) is by far the most abundant product (Scheme-I) when the reaction takes place at close to ambient conditions ${ }^{3}$. So the critical role of

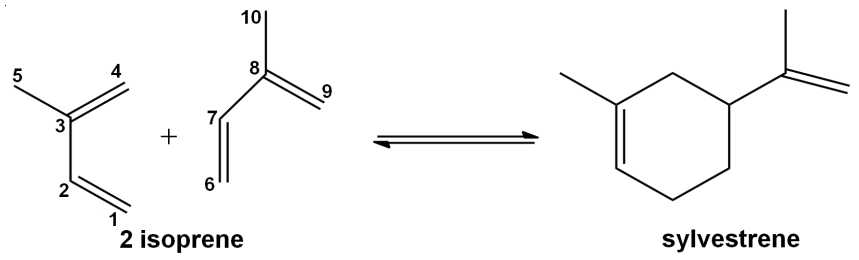

Scheme-I: Sylvestrene synthesis by cycloaddition reaction between 2 isoprenes the study on the Diels-Alder cycloadditions of sylvestrene from isoprene is well appreciated.

The mechanisms of the Diels-Alder reaction, which perhaps is the most widely utilized method for the construction of six-membered rings in synthetic organic chemistry ${ }^{4-7}$ and a well-known theoretical model for pericyclic reactions ${ }^{8,9}$, have been the subject of the most interesting controversies ${ }^{10-13}$. Both experimental data and theoretical calculations indicate that the reaction occurs through a concerted mechanism. Although, in some cases, stepwise mechanisms involving biradical intermediates are only slightly less favorable. However, because of the remarkably similarity ${ }^{14}$ of the energies between concerted and stepwise mechanisms, it is yet not clear as to which mechanism occurs for individual cases involving various substitutions. In this work, we address an asynchronous concerted mechanism of the cyclodimerization of isoprene characterized by chemical hardness and intrinsic reaction coordinates. The influence of different molecular orientation, reactant conformation and electron density of the frontier orbital are also analyzed.

\section{EXPERIMENTAL}

The stationary points (reactants, products and transition states) are full optimized and characterized by vibrational frequency calculations using three different methods. One is 
carried out at the 6-31G(d) basis set with second-order MøllerPlesset perturbation (MP2) theory, the others applied B3LYP (Becke's three-parameter-hybrid functional combined with the correlation function of Lee et al. ${ }^{15-20}$ ) density functional with the 6-31G(d) and 6-311++G(d,p) basis set, respectively. All minima and transition structures are confirmed to have none or only one imaginary frequency, respectively. Intrinsic reaction coordinates analyse ${ }^{21}$ are followed to determine the connections between the transition structures and the minima. The population analysis of the reactants molecular orbital and single point calculations are performed on the B3LYP/6-311++G(d,p) geometries using larger basis set 6-311++G (3df,2p) with mp2 to obtain more reliable energies. All calculations are performed with Gaussian $03^{22}$.

\section{RESULTS AND DISCUSSION}

Concerted transition states: According to the rule of diene synthesis, the two double bonds of the conjugated system in the diene must be in the cis-configuration with each other or else must rearrange to such a configuration before addition can occur ${ }^{3}$. While the isoprene which acts as dienophile may be either in cis- or trans-configuration. Consequently, there are four different reaction pathways, i.e., cis-exo, trans-exo, cis-endo and trans-endo, which are named according to the configuration and orientation of dienophile. RC1-4, TS1-4 and P1-4 are used to indicate the reaction complexes, transition states and products of each pathway, respectively. The stable reaction intermediates which represent the stepwise mechanism are not found in our calculations. Therefore, our discussion will focus mainly on the concerted pathway in this work. The main geometry parameters of the four concerted transition states are given in Fig. 1 for different methods and basis sets.

Compared to the DFT methods, the single bond, such as $\mathrm{C} 2-\mathrm{C} 3$ or $\mathrm{C} 7-\mathrm{C} 8$ length of the isoprene monomer (carbon atom labeled according to Scheme-I) optimized with the MP2 method are little shorter, while the double bonds such as $\mathrm{C} 1-$ C2, C3-C4 and C6-C7 are longer. However, the corresponding bonds length in the concerted transition states change reversely. That is, the degree of variation of the DFT value is greater than the MP2 value. The trends of the original single bonds change into double bonds and the double bonds into single bonds in the transition states calculated at the DFT levels is

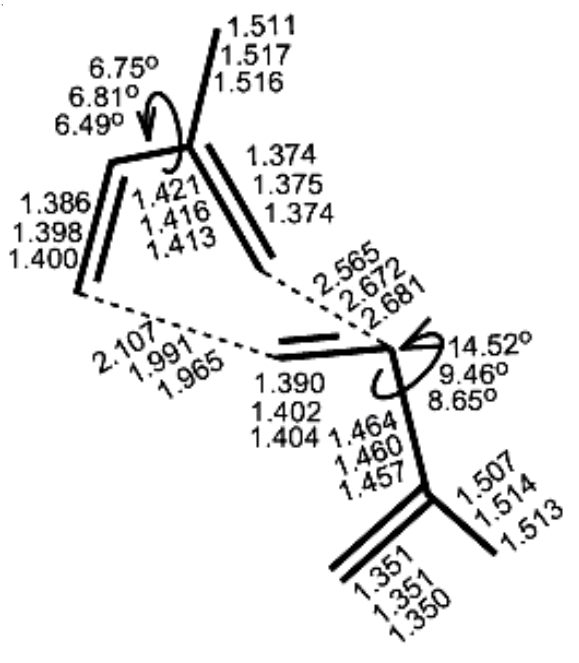

TS1 (cis_exo)

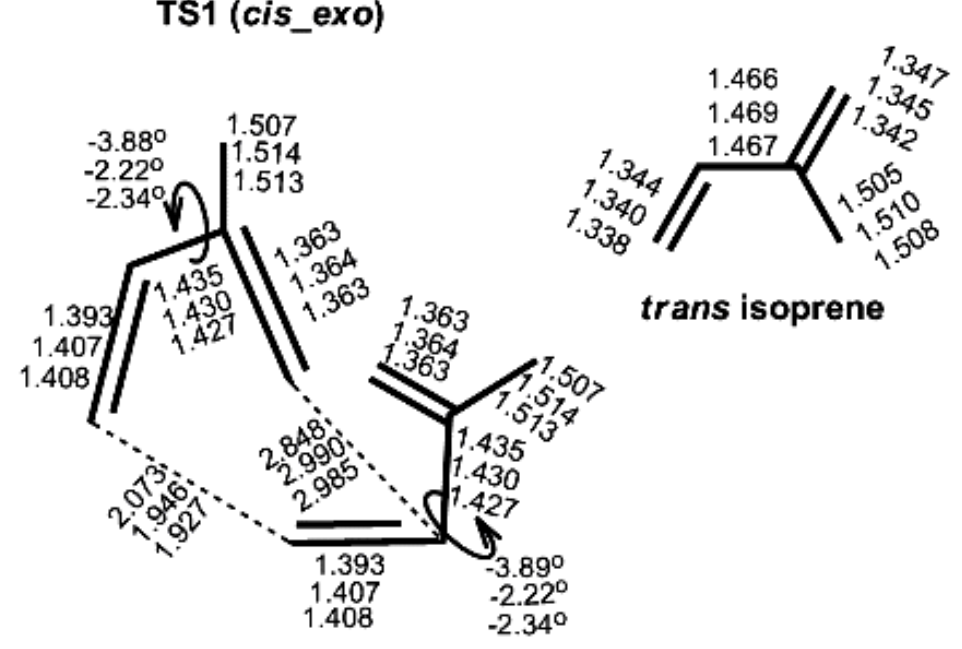

TS3 (cis_endo)

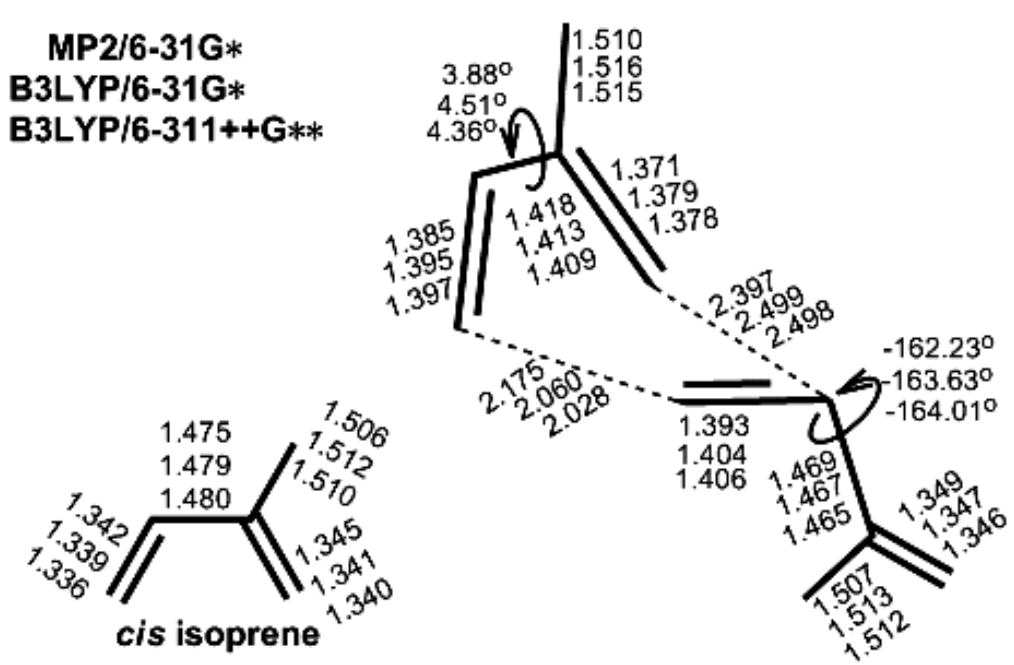

TS2 (trans_exo)

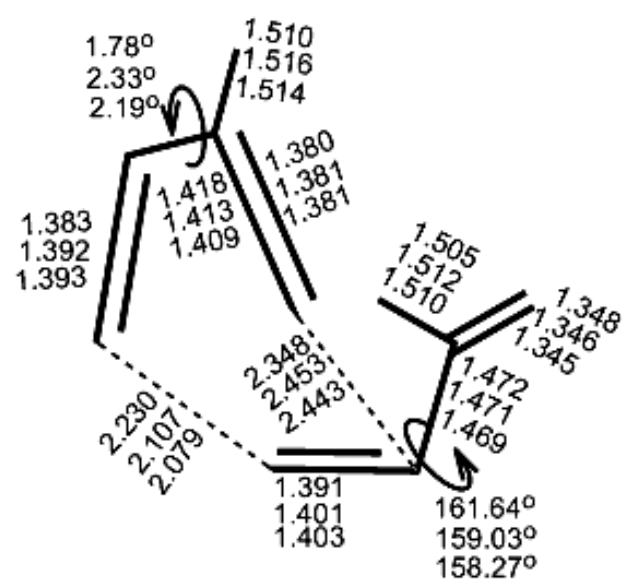

TS4 (trans_endo)

Fig. 1. Optimized geometries of isoprene the transition states of the four synthesis reactions using different computational level (distances in $\AA$ and dihedral angles in degree) 
more obvious than that at the MP2 level. The MP2 computed transition states might look more like the reactants and the DFT transition states are more similar to the products. The largest difference $(>0.1 \AA$ ) is found for the intermolecular distance of C1-C6 and C4-C7. One can see that the distances of $\mathrm{C} 1-\mathrm{C} 6$ and $\mathrm{C} 4-\mathrm{C} 7$ depend on the computational method more and do not depend very much on the basis set.

The dihedral values in Fig. 1 have little difference and all the cis structures are close to the plane, while the trans structures have a certain gauche conformation. Fig. 2 showed that the energy barriers of the reactions involved with the transdienophiles are relatively higher, which may be resulted from that the trans dienophiles may first convert themselves to gauche confrontation with a relative higher energy to form the transition states.

The relative energy barrier of TS3 is the lowest in all four transition states (Table-1), which suggests that secondary orbital interaction $^{23}$ may be exist between the non-bonded atoms such as $\mathrm{C} 3-\mathrm{C} 8$ or $\mathrm{C} 2-\mathrm{C} 9$ in the two endo approaching reactant monomers. The distance of $\mathrm{C} 3-\mathrm{C} 8$ and $\mathrm{C} 2-\mathrm{C} 9$ are about $3 \AA$ and $2.8 \AA$, respectively. We think that the secondary interaction may increase the stability of the transition state and reduce its potential energy. In view of the electron cloud density distribution of the frontier orbits is mainly localized at the conjugated double bond and there is little distribution in the methyl group, the secondary interaction may be very weak in the endo additional TS4. In exo additional TS1 and TS2 there may not present the secondary interaction because two reactant planes are far away from each other.

Energies profiles and the products structure: The relative energies of all the stagnation points in the reaction pathway corrected by zero-point vibrational energies (ZPVE) can be seen in Table-1. The differences of the relative energies calculated by different basis set with B3LYP method were little. While the difference between the reaction complex and the transition states $(\mathrm{TS})$ at $6-311++\mathrm{G}(\mathrm{d}, \mathrm{p})$ level were slightly higher than that at 6-31G(d).

The differences between the 6-31G(d) results of DFT and MP2 methods are more obvious: the energy differences between $\mathrm{RC}$ and the summation of two isoprene monomers are larger for the latter, while the potential energy barriers between RC and TS are lower. Squillacote and his coworkers ${ }^{24}$ have found that the dihedral of butadiene optimized by DFT method were smaller than that of HF, MP2 and CCSD methods when they studied the conformation kinetics of the methylsubstituted derivatives of 1,3-butadiene. Similarly, we find in our study that the geometric structure of the trans_endo product (P4) optimized by MP2 method was not similar to that by DFT method (Fig. 2) and the relative energy of P4 was the highest among the four products calculated by MP2, too. We suggest that the results of DFT and post HF methods (such as MP2) may have certain difference for methyl-substituted derivatives of butadiene.

Thus we ultimately chose B3LYP/6-311++G(d, p) optimized results to model the reaction pathway and calculated the single point energies at higher basis set with MP2 method in order to obtain more credible energy values (Fig. 3). Later discussions are all based on these results unless otherwise stated.

The relative energies of the products formed by trans reactants were lower than those by cis reactants, but the potential energy surfaces of the formers were slightly steeper (Fig. 3). We think P3 may be more favorable because the energy barrier of P3 formation is the lowest despite its potential

TABLE-1

CALCULATED TOTAL ENERGIES (E, Hartree), ZERO-POINT VIBRATIONAL ENERGIES (ZPVE, kJ/mol), ZPVE-CORRECTED RELATIVE $\operatorname{ENERGIES~}^{\mathrm{a}}(\triangle \mathrm{E}, \mathrm{kJ} / \mathrm{mol})$ AND THE IMAGINARY FREQUENCIES (IMG, $\left.\mathrm{cm}^{-1}\right)$ OF THE STATIONARY POINT STRUCTURES FOR SYNTHESIS OF SYLVESTRENE BY THE DIELS-ALDER REACTION OF TWO ISOPRENES

\begin{tabular}{|c|c|c|c|c|c|c|c|c|c|c|c|}
\hline \multirow[t]{2}{*}{ Species } & \multicolumn{3}{|c|}{ B3LYP/6-31g(d) } & \multicolumn{3}{|c|}{ B3LYP/6-311++g(d, p) } & \multicolumn{3}{|c|}{ MP2/6-31g(d) } & \multicolumn{2}{|c|}{$\begin{array}{l}\text { MP2/6-311++g(3df, 2p) } \\
/ / \text { B3LYP/6-311++g(d, p) }\end{array}$} \\
\hline & IMG & ZPVE & $\Delta \mathrm{E}$ & IMG & ZPVE & $\Delta \mathrm{E}$ & IMG & ZPVE & $\Delta \mathrm{E}$ & $\mathrm{E}$ & $\Delta \mathrm{E}$ \\
\hline$c i s$-isoprene & -105.75 & 297.76 & 0.00 & -109.46 & 294.76 & 0.00 & -167.27 & 302.00 & 0.00 & -194.837962 & 0.00 \\
\hline trans-isoprene & & 299.62 & -13.55 & & 296.57 & -14.00 & & 303.40 & -13.94 & -194.844371 & -15.02 \\
\hline cis + cis isoprene & & & 0.00 & & & 0.00 & & & 0.00 & -389.675924 & 0.00 \\
\hline $\begin{array}{c}\text { cis +trans isoprene } \\
\text { cis }+ \text { cis_exo }\end{array}$ & & & 0.00 & & & 0.00 & & & 0.00 & -389.682333 & 0.00 \\
\hline TS1 & -487.09 & 603.55 & 84.77 & -488.38 & 597.36 & 96.09 & -501.43 & 611.35 & 49.40 & -389.668835 & 26.45 \\
\hline $\mathrm{P} 1$ cis+trans_exo & 621.43 & -137.84 & & 615.05 & -111.05 & & 633.21 & -197.02 & -389.758373 & -190.94 & \\
\hline $\mathrm{RC} 2$ & & 599.62 & -4.78 & & 592.79 & -1.91 & & 608.21 & -18.62 & -389.685975 & -8.10 \\
\hline TS2 & -516.90 & 604.14 & 100.85 & -526.43 & 597.83 & 113.71 & -495.90 & 611.90 & 64.20 & -389.667980 & 44.18 \\
\hline P2 cis+cis_endo & & 620.09 & -139.62 & & 613.86 & -112.78 & & 631.50 & -194.12 & -389.762105 & -186.91 \\
\hline $\mathrm{RC} 3$ & & 598.76 & -7.54 & & 592.03 & -5.14 & & 607.94 & -26.38 & -389.684391 & -19.72 \\
\hline $\begin{array}{l}\mathrm{P} 3 \\
\quad \text { cis+trans_endo }\end{array}$ & & 621.43 & -137.84 & & 615.05 & -111.05 & & 633.21 & -197.02 & -389.758372 & -190.93 \\
\hline $\mathrm{RC} 4$ & & 599.56 & -4.86 & & 592.71 & -2.38 & & 607.79 & -18.37 & -389.687012 & -10.90 \\
\hline TS4 & -518.74 & 604.32 & 104.71 & -532.49 & 597.84 & 117.65 & -486.44 & 612.29 & 64.36 & -389.667897 & 44.41 \\
\hline P4 & & 620.09 & -139.62 & & 613.86 & -112.78 & & 631.20 & -173.07 & -389.762137 & -186.99 \\
\hline
\end{tabular}

${ }^{*} \mathrm{RC}$ : reaction complex, TS: transition state, P: product

a: Relative energy of each stationary point is according to the sum of the corresponding isoprene monomers of each pathway. The relative energy of trans isoprene is according to the cis isoprene. 


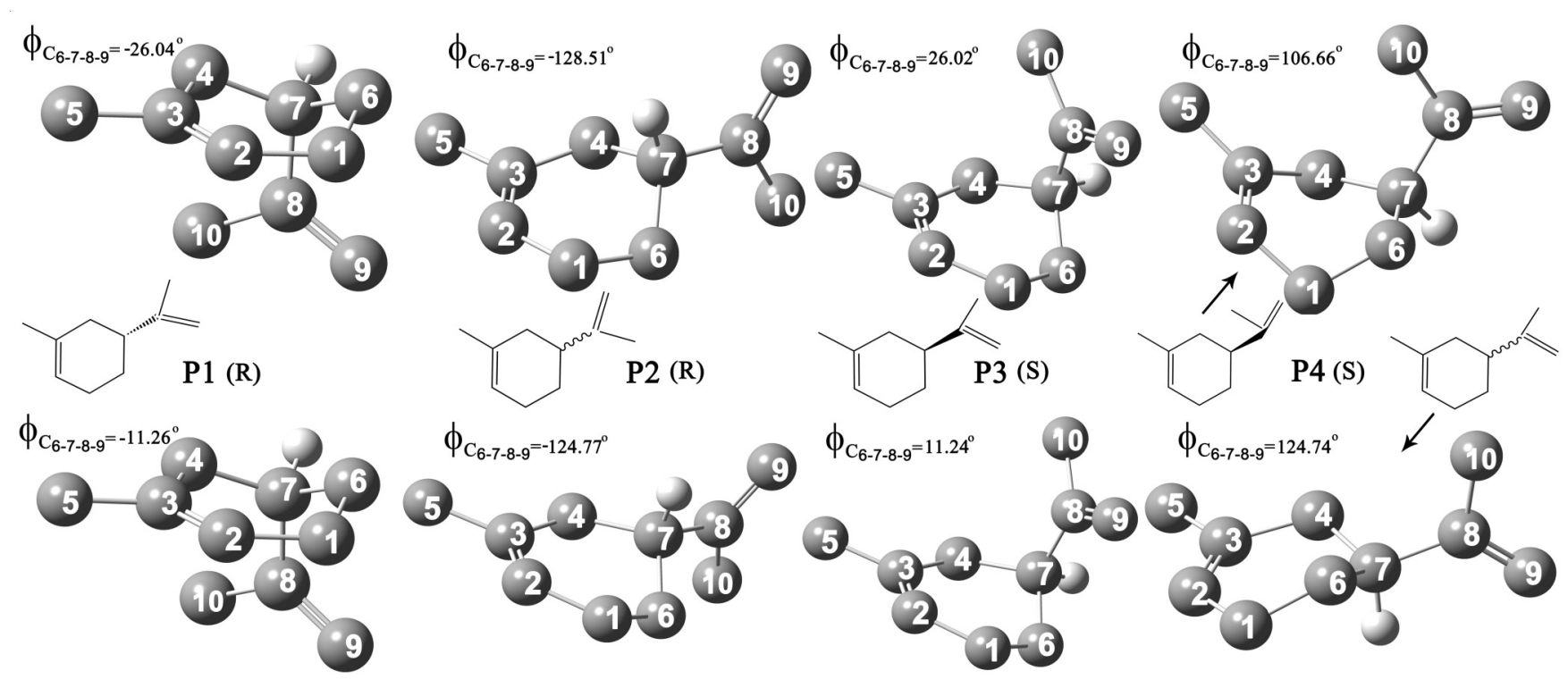

Fig. 2. Optimized geometries of the four products (hydrogen atoms are not shown except that on C7). up: MP2/6-31G*, down: B3LYP/6-311++G**

energy is not the lowest. Taking into account the conformational transition from cis- to trans-isoprene is easy (the potential energy barrier in our calculation is only about $11 \mathrm{~kJ} / \mathrm{mol}$ which is close to the experimental value $\mathrm{e}^{25}$ ) and the barrier of the transition from $\mathrm{P} 1$ to $\mathrm{P} 2$ is only $15 \mathrm{~kJ} / \mathrm{mol}$ based on our calculation. It is suggested that there would be two pathway if RC1 (or $\mathrm{RC} 3$ ) forms $\mathrm{P} 2$ (or P4) through the cycloaddition reaction. One is the cis-dienophile converts itself to trans-conformation first, another is generate P1 (or P3) directly, then converted conformation into P2 (or P4). The thermodynamical difference between the two paths was about only $4 \mathrm{~kJ} / \mathrm{mol}$.

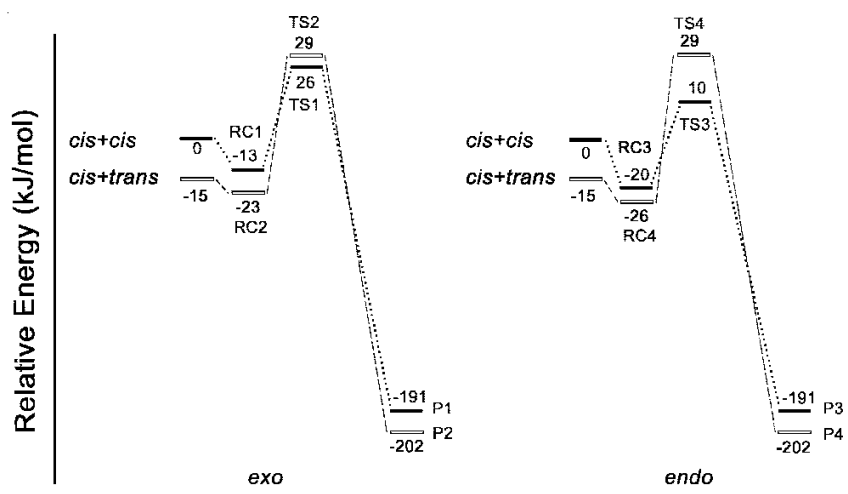

Fig. 3. Potential energy profiles at MP2/6-311++G(3df, 2p)//B3LYP/6$311++\mathrm{G}^{* *}$ level for the four reaction pathway (the reaction energies involved with trans-dineophile are decreased by $15 \mathrm{~kJ} / \mathrm{mol}$ which is the difference between cis and trans-isoprene)

Cycloaddition of 1,3-butadiene with ethylene is the most studied model for Diels-Alder reaction and its experimental energy barrier is $27.5 \mathrm{kcal} / \mathrm{mol}^{26}$ which is lower than many theoretical value ${ }^{14}$. The results of B3LYP and MP2 methods are usually consistent with the experimental values well. Although there have no experimentally determined activation energies of isoprene dimerization up to now, our calculation show that those energy barriers are much lower than 1,3-butadiene and ethylene cycloaddition. We suggest that being a electron donor the methyl substituent enhances the activity of the dienophiles and make the reactions can occur at room temperature, which is consistent with the known experimental phenomenon $^{3}$.

The products of exo (P1 and $\mathrm{P} 2)$ and endo addition (P3 and $\mathrm{P} 4$ ) are enantiomers (Fig. 2). The formers are right-handed (R) sylvestrenes, the latter are the left-handed (S). P1 and P2 are conformational isomers. The energy difference between them is about $11 \mathrm{~kJ} / \mathrm{mol}$ despite both their reaction orientation and optical activities are same. P1 is formed from the addition of the cis-dienophile and P2 comes from trans-dienophile. Different conformation reactants result in different conformation products. It is the same with $\mathrm{P} 3$ and $\mathrm{P} 4$. On the other hand, the relative energy of $\mathrm{P} 1$ and $\mathrm{P} 3$ are very close despite that they have different configurations and they all are the products of the cis reactants. The relative energy of $\mathrm{P} 2$ and $\mathrm{P} 4$ are also nearly same and they all are the products of the transdienophiles.

Characteristics of asynchronous concerted reaction: The bonds distances that are being formed in TS1-4, C1-C6 and $\mathrm{C} 4-\mathrm{C} 7$, are not same. All the $\mathrm{C} 4-\mathrm{C} 7$ distances are longer than $\mathrm{C} 1-\mathrm{C} 6$ and the differences between them are about 0.3-1 $\AA$. The differences in TS1 and TS3 which are formed from cis dienophile are longer than those in TS2 and TS4, especially the cis_endo TS3 (more than $1 \AA$ ). Considering that the bond lengths of the full formed $\mathrm{C} 1-\mathrm{C} 6$ and $\mathrm{C} 4-\mathrm{C} 7$ bonds in the products are not same. The difference between the ratios of the forming bond distances in the TS and the corresponding bond lengths in the product is defined as the asynchronous degree of the concerted reaction ${ }^{27,28}$, i.e., $\Delta \mathrm{d}_{\mathrm{TS} / \mathrm{P}}=d(\mathrm{C} 4-\mathrm{C} 7) \mathrm{TS} /$ $d(\mathrm{C} 4-\mathrm{C} 7)_{\mathrm{P}^{-} d}(\mathrm{C} 1-\mathrm{C} 6) \mathrm{TS} / d(\mathrm{C} 1-\mathrm{C} 6) \mathrm{P}$ and the " $d$ " value indicates the distance between two special atoms. Evidently, in the case of a totally synchronous reaction the $\Delta d_{\mathrm{TS} / \mathrm{P}}$ value is 0 . Table- 2 showed that all $\Delta d_{\mathrm{TS} / \mathrm{P}}$ values are positive which suggestes that C1-C6 always forms bond first in all reactions. The asynchronous degree of cis-endo reaction (TS3) is the greatest.

Though the results of $\Delta d_{\mathrm{TS} / \mathrm{P}}$ can indicate which bond would form first, only two stagnation points in the path are considered and the reaction process details lack. From the 
results (Fig. 4) of intrinsic reaction coordinates calculation at B3LYP/6-311++G(d,p) level (stepsize $=0.1 \mathrm{amu} 1 / 2$ bohr) we can see that the formation of all the new bonds take place between the TSs and the products and no stable intermediates exist. The coordinates of the TSs are near to the reactant complexes in the reactions involved with cis-dienophiles, especially the cis-endo reaction. The intervals between two new bonds forming are long and the potential energies decrease a lot. The asynchronous characters of the reactions are very obvious. While in the reactions with trans-dienophiles the TSs are near to the products more, especially the trans-exo reaction. The intervals between two new bonds forming are very short and the potential energies decrease a little, which are more like the synchronous reactions.

\begin{tabular}{cccc}
\multicolumn{4}{c}{ TABLE-2 } \\
\multicolumn{4}{c}{$\begin{array}{c}\text { ASYNCHRONICITY }\left(\Delta d_{\text {TS/P }}\right) \text { IN THE } \\
\text { BOND-FORMATION PROCESS }\end{array}$} \\
\hline \multirow{3}{*}{$\begin{array}{c}\text { Transition } \\
\text { states }\end{array}$} & \multicolumn{3}{c}{$\Delta d_{\text {TS/P }}$} \\
\cline { 2 - 4 } & MP2/6-31G* & B3LYP/6-31G* & B3LYP/6- \\
\hline TS1 & 0.295 & 0.432 & 0.455 \\
TS2 & 0.144 & 0.274 & 0.297 \\
TS3 & 0.501 & 0.666 & 0.677 \\
TS4 & 0.056 & 0.214 & 0.227 \\
\hline
\end{tabular}
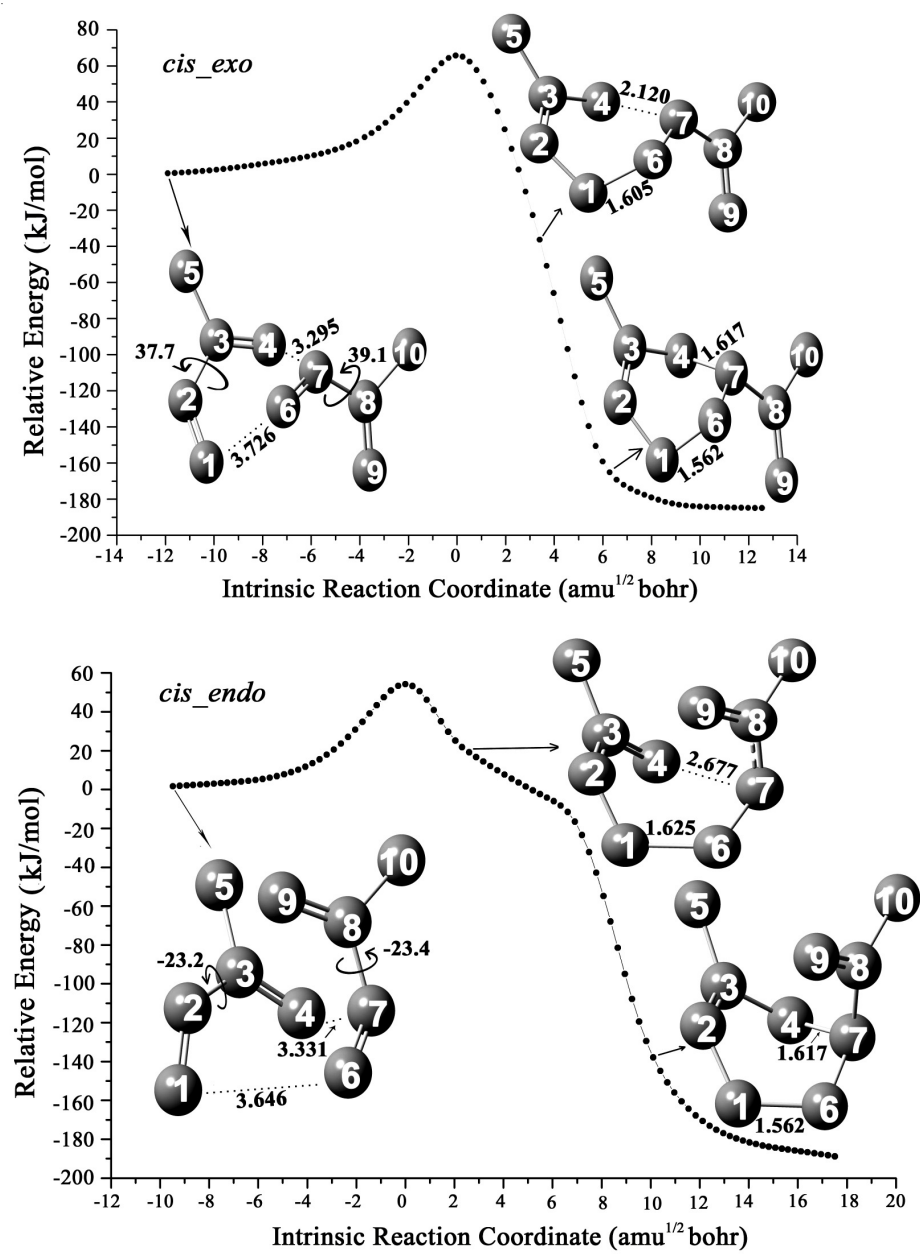

The degree of the synchronous difference can be seen more clearly from the change of the bond distances between C1-C6 and C4-C7 along the reaction coordinates (Fig. 5). As the cis dienophiles reactions proceed the $\mathrm{C} 1-\mathrm{C} 6$ bond distance is less than $\mathrm{C} 4-\mathrm{C} 7$ bond distance gradually and enters bonding range first despite the former is much longer at the very beginning. There is an obvious turning point at the C4-C7 distance curve of cis_endo reaction, just likes the "shoulder" in the cis_endo potential energy surface in Fig. 4. It suggests that this position is a critical point of structural conversion and the distance between C4-C7 and the potential energy of the reaction system decrease more quickly from this point.

From the dihedral angles variation profiles of $\mathrm{C}_{1-2-3-4}$ and $\mathrm{C}_{6-7-8-9}$ we can see that all $\mathrm{cis}$ reactants dihedral angles become small first and large later during the reactions progress and small again gradually at the end. The complex of the dihedral conversion may be used to explain what have happened in the long intervals between two new bonds forming.

Pearson proposed a maximum hardness principle (MHP) according to the principle, 'there seems to be a rule of nature that molecules arrange themselves so as to be as hard as possible $^{29}$. A large number of calculations have confirmed this principle and found that the hardness of the product always tends to be the maximum, while the TS is the minimum. But many researches in recent years show that it is not valid for all the
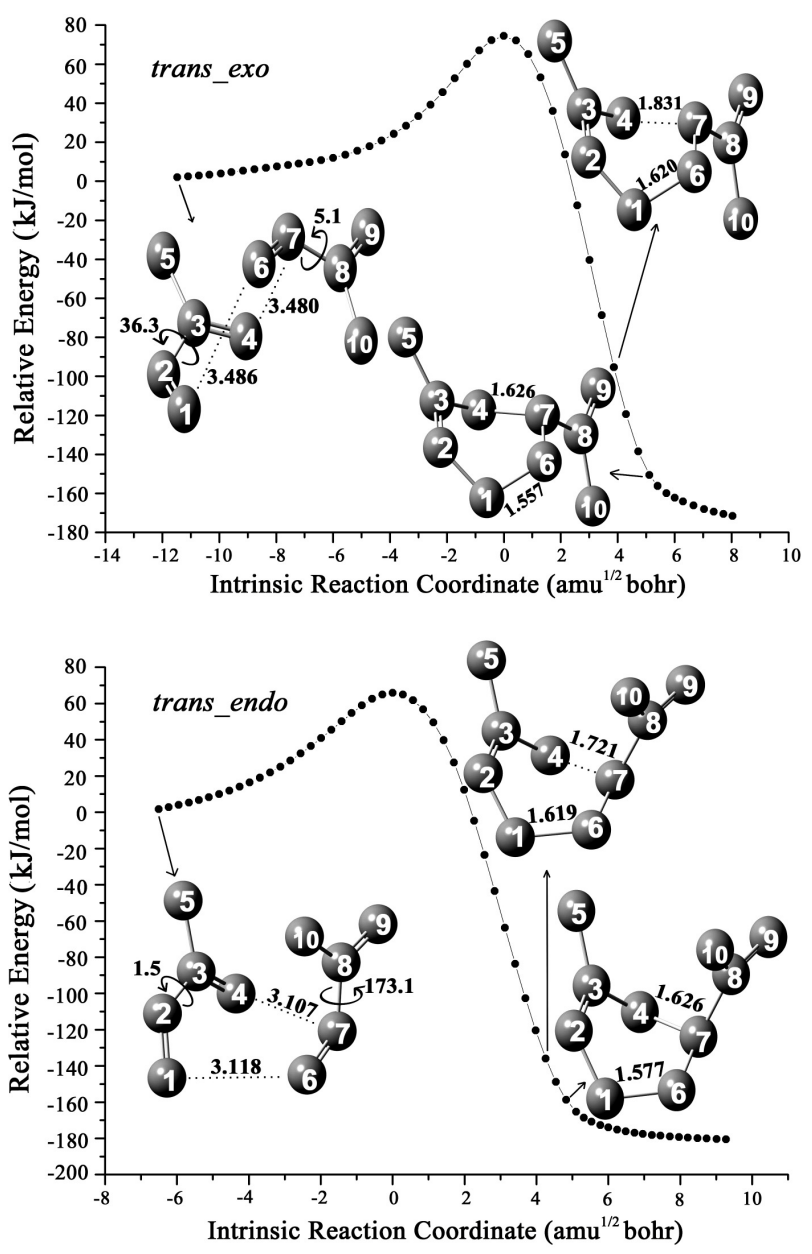

Fig. 4. Energy profiles (B3LYP/6-311++G**) along the intrinsic reaction coordinate for the four synthesis reactions of sylvestrene from two isoprenes, including the geometries of selected saddle points marked by the distances between two bonding atoms (hydrogen are not shown, distances in $\AA$, dihedral angles in degree) 

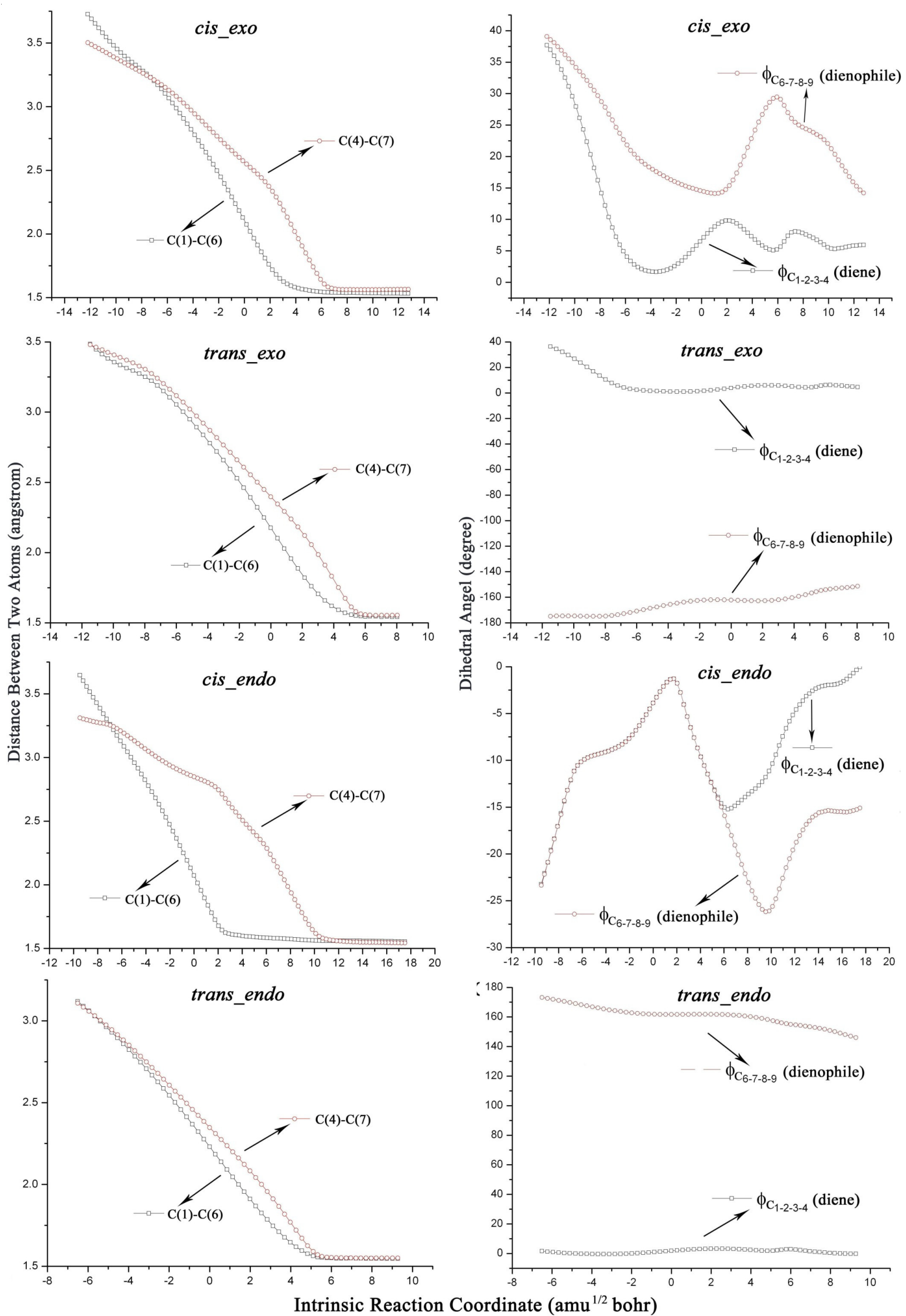

Fig. 5. Distances between specific atoms (left) and angles of specific dihedrals (right) along intrinsic reaction coordinate (distances in $\AA$, dihedral angles in degree) 
reactions. Based on the calculations by Labet et al. ${ }^{30}$, a hardness profile presenting a minimum shifted with respect to the transition state is a indicator of the presence of an asynchronous concerted mechanism. In our results (Fig. 6) of the chemical hardness along the intrinsic reaction coordinates calculated by formula $(1)^{31}$ we find that the hardness of TS1-4 are all not the minimum. The minimum values present at the position about 0.8-2 amu1/2 bohr from TSs to the products. All four reaction pathways have asynchronous characteristics according to Labet et al. view. The maximum shift appears in cis-endo pathway, which indicates that it is the most obvious asynchronous reaction and is consistent with the results mentioned previously in this paper. Moreover, there is an obvious turning point in the hardness profile of cis-endo path, which is also consistent with the "shoulder" in the corresponding potential energy profile in Fig. 4.

$$
\eta=\left(\varepsilon_{\mathrm{LUMO}}-\varepsilon_{\mathrm{HOMO}}\right) / 2
$$

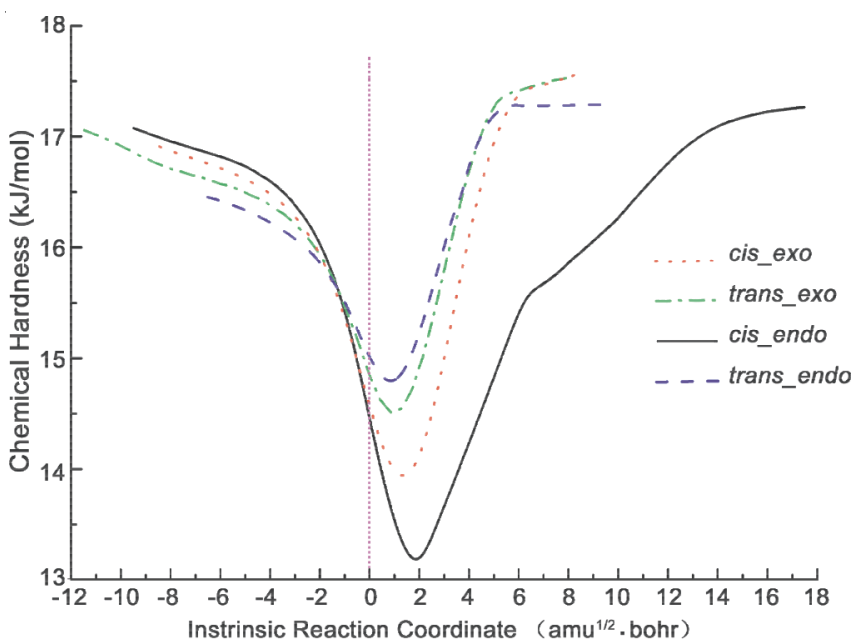

Fig. 6. Chemical hardness profiles (purple vertical dashed line indicates the position of the TS step)

Why C1-C6 forms bond first in all reactions instead of C4-C7? We think it can be interpreted with the contributions of different atoms to the frontier orbital. The numbers in Fig. 7 indicate the electron densities of the HOMO (highest occupied molecular orbital) and LUMO (lowest unoccupied molecular orbital), that is, the per cent of the contribution to the frontier orbital of each atom calculated by the following two formulae:

$$
\rho_{\mathrm{i}_{-} \text {номо }}=\mathrm{C}_{\mathrm{i}}^{2} / \sum_{\mathrm{i} \in \mathrm{o}} \mathrm{C}_{\mathrm{i}, \mathrm{HOMO}}^{2} \times 100 \%
$$

$$
\rho_{\mathrm{i}_{-} \text {LUMO }}=\mathrm{C}_{\mathrm{i}}^{2} / \sum_{\mathrm{i} \in \mathrm{O}} \mathrm{C}_{\mathrm{i}, \mathrm{LUMO}}^{2} \times 100 \%
$$

In these formulae $\mathrm{C}_{\mathrm{i}}$ is the contribution to the frontier orbital (HOMO or LUMO) of atom i, which is the sum of squares of all the orbital coefficients of atom i contributed to the frontier orbital. $\mathrm{O}$ in the formulae indicates that all the carbon atoms of isoprene molecule. We can see the terminal carbon atoms of the double bond contribute more to the frontier orbital than the inside carbon atoms of the double bond. Specifically, the HOMO distribution on $\mathrm{C} 1, \mathrm{C} 4$ and $\mathrm{C} 6$ are more than $\mathrm{C} 2, \mathrm{C} 3$ and C7, respectively, which indicate that the electrondonating ability of the former is stronger than the latter. Meanwhile, the LUMO distribution on $\mathrm{C} 1, \mathrm{C} 4$ and $\mathrm{C} 6$ are also more than $\mathrm{C} 2, \mathrm{C} 3$ and $\mathrm{C} 7$, which indicate that the electron-withdrawing ability of the former is stronger than the latter, too. Table-3 listed all the products multiplied by different electron densities of each two bonding atoms from different HOMO/ LUMO combinations, which are used to represent the relative bonding capacity of each atom pair. All the products of C1-C6 are greater than $\mathrm{C} 4-\mathrm{C} 7$, which explains the phenomenon that C1-C6 is always bonding first. The biggest gap between C1-C6 and C4-C7 is 945.03 and 433.62 in the cis-LUMO/ trans-HOMO combination, while the asynchronous degrees of cis-trans reactions are not great than cis-cis reactions. It suggests that the asynchronous degree may be determined by many factors, such as the electron density of the frontier orbital,

\begin{tabular}{|c|c|c|}
\hline \multicolumn{3}{|c|}{$\begin{array}{c}\text { TABLE } 3 \\
\text { PRODUCT OF THE DENSITY OF FMO AT C1, } \\
\text { C4, C6 AND C7 OF ISOPRENE }\end{array}$} \\
\hline Serial & Expression & Results \\
\hline cis-HOMO-C1 × cis-LUMO-C6 & $26.6 \times 32.7$ & 869.82 \\
\hline cis-HOMO-C4 × cis-LUMO-C7 & $33.6 \times 19.2$ & 645.12 \\
\hline cis-LUMO-C1 × cis-HOMO-C6 & $32.7 \times 26.6$ & 869.82 \\
\hline cis-LUMO-C4 × cis-HOMO-C7 & $29.7 \times 15.7$ & 466.29 \\
\hline cis-HOMO-C1 $\times$ trans-LUMO-C6 & $26.6 \times 30.9$ & 821.94 \\
\hline cis-HOMO-C4 × trans-LUMO-C7 & $33.6 \times 17.7$ & 594.72 \\
\hline cis-LUMO-C1 $\times$ trans-HOMO-C6 & $32.7 \times 28.9$ & $945 .-3$ \\
\hline cis-LUMO-C4 × trans-HOMO-C7 & $29.7 \times 14.6$ & 433.62 \\
\hline
\end{tabular}
reactant conformation, molecular orientation and the substituent positions.

Addition from the other face: In addition to the four reaction pathways discussed above, the isoprene monomer molecules which act as dienophiles can also approach the dienes from the other face, as shown in Fig. 8. Both HOMO-
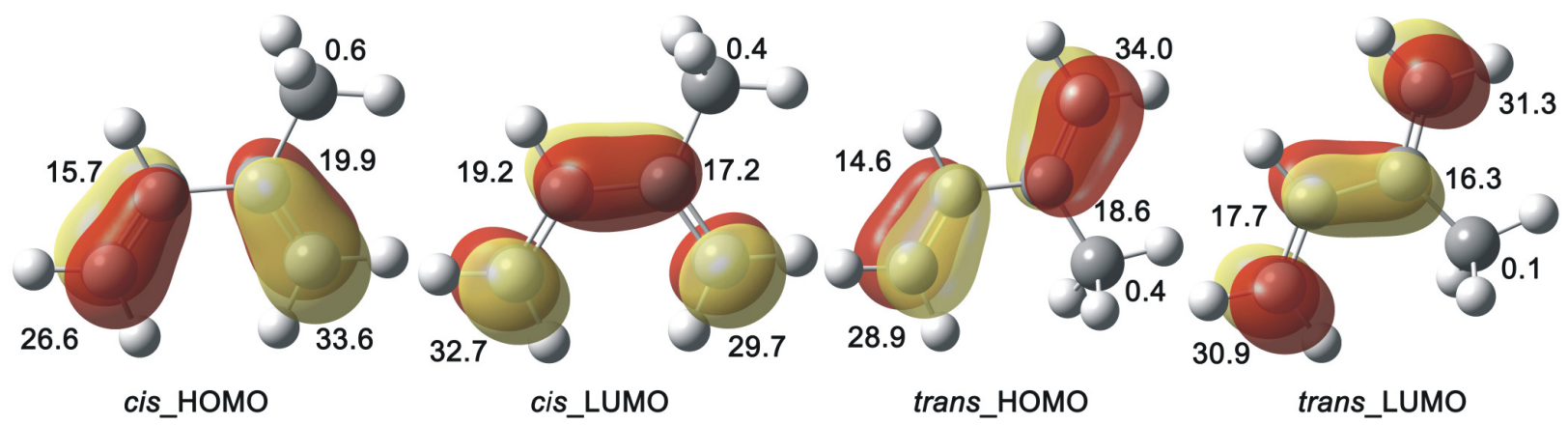

Fig. 7. HOMO and LUMO of isoprene (isovalue $=0.05$ ) 
LUMO interactions are symmetry allowed, too. The asynchronous features of the four concerted transition states and the reaction pathway are very similar to those discussed above. Due to the asymmetry of isoprene itself, each transition state and product are the enantiomers of those in the pathways discussed above, that is, (a), (b), (c) and (d) are the enantiomers of TS1, TS2, TS3 and TS4, respectively. Corresponding products are similar to $\mathrm{P} 3, \mathrm{P} 4, \mathrm{P} 1$ and $\mathrm{P} 2$, too.<smiles>C=CC(=C)C1CCCC1C(=C)C</smiles>

(a)

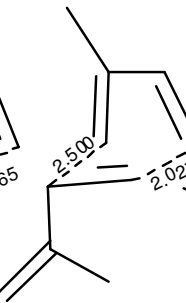

(b)

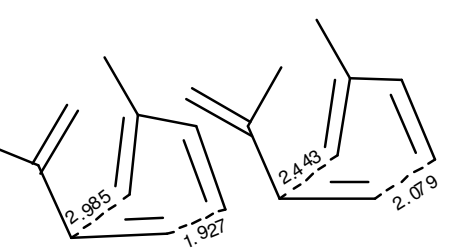

(c)

(d)
Fig. 8. Geometries of four transition states when dienophile approaches the diene from another face (B3LYP/6-311++G**)

\section{Conclusion}

According to the change of the molecular structures, structure characteristics of the transition states, chemical hardness and electron density of frontier orbital, we suggest the isoprene cyclization polymerization are asynchronous concerted reactions. The asynchronous degree may be depended on the frontier orbital electron distribution, the conformation and the approaching orientation of the reactants. All the difference of the relative energy of each pathway are little and cis_endo reaction may be the main pathway in all eight reaction channels.

\section{ACKNOWLEDGEMENTS}

This work was supported by Scientific Major Project of China National Tobacco Corporation (110201001001), Scientific Development Plan of China Tobacco Yunnan Industrial Company (2010JC04) and Natural Science Foundation of Yunnan Province of China (2013FZ120).

\section{REFERENCES}

1. J.D. Grossman, R.M. Ikeda, E.J. Deszyck and A. Bavley, Nature, 199, 661 (1963).

2. R.F. Severson. W.S. Schlotzhauer, O.T. Chortyk, R.F. Arrendale and M.E. Snook, in eds.: P.W. Jones and P. Leber, Precursors of Polynuclear
Aromatic Hydrocarbons in Tobacco Smoke, In: Polynuclear Aromatic Hydrocarbons, Ann Arbor Science, Ann Arbor, Michigan, pp. 1-277 (1979).

3. J.A. Norton, Chem. Rev., 31, 319 (1942).

4. O. Diels and K. Alder, Justus Liebigs Ann. Chem., 460, 98 (1928).

5. A. Wasserman, Diels-Alder Reactions-organic background and Physicochemical Aspects, Elsevier, New York (1965).

6. J. Hamer, 1,4-Cycloaddition Reactions: the Diels-Alder Reaction in Heterocyclic Syntheses, Academic Press, London (1967).

7. K.C. Nicolaou, S.A. Snyder, T. Montagnon and G. Vassilikogiannakis, Angew. Chem. Int. Ed., 41, 1668 (2002).

8. R.B. Woodward and T.J. Katz, Tetrahedron, 5, 70 (1959).

9. K.N. Houk, J. Gonzalez and Y. Li, Acc. Chem. Res., 28, 81 (1995).

10. Y. Li and K.N. Houk, J. Am. Chem. Soc., 115, 7478 (1993).

11. S. Sakai, J. Phys. Chem. A, 104, 922 (2000).

12. S. Sakai, J. Mol. Struct. (Theochem), 630, 177 (2003).

13. S. Sakai and T. Okumura, J. Mol. Struct. (Theochem), 685, 89 (2004).

14. S.M. Bachrach, Pericyclic Reactions, In: Computational Organic Chemistry, John Wiley \& Sons, Inc., Hoboken, N.J., pp. 1-117 (2006).

15. P.J. Hay, J. Chem. Phys., 66, 4377 (1977).

16. A.D. McLean and G.S. Chandler, J. Chem. Phys., 72, 5639 (1980).

17. M. Head-Gordon, J.A. Pople and M.J. Frisch, Chem. Phys. Lett., 153, 503 (1988).

18. C. Lee, W. Yang and R.G. Parr, Phys. Rev. B, 37, 785 (1988).

19. G.A. Petersson, A. Bennett, T.G. Tensfeldt, M.A. Al-Laham, W.A. Shirley and J. Mantzaris, J. Chem. Phys., 89, 2193 (1988).

20. A.D. Becke, J. Chem. Phys., 98, 1372 (1993).

21. K. Fukui, J. Chem. Phys., 74, 4161 (1970).

22. M.J. Frisch, G.W. Trucks, H.B. Schlegel, G.E. Scuseria, M.A. Robb, J.R. Cheeseman, G. Scalmani, V. Barone, B. Mennucci, G.A. Petersson, H. Nakatsuji, M. Caricato, X. Li, H.P. Hratchian, A.F. Izmaylov, J. Bloino, G. Zheng, J.L. Sonnenberg, M. Hada, M. Ehara, K. Toyota, R. Fukuda, J. Hasegawa, M. Ishida, T. Nakajima, Y. Honda, O. Kitao, H. Nakai, T. Vreven, J.J.A. Montgomery, J.E. Peralta, F. Ogliaro, M. Bearpark, J.J. Heyd, E. Brothers, K.N. Kudin, V.N. Staroverov, R. Kobayashi, J. Normand, K. Raghavachari, A. Rendell, J.C. Burant, S.S. Iyengar, J. Tomasi, M. Cossi, N. Rega, J.M. Millam, M. Klene, J.E. Knox, J.B. Cross, V. Bakken, C. Adamo, J. Jaramillo, R. Gomperts, R.E. Stratmann, O. Yazyev, A.J. Austin, R. Cammi, C. Pomelli, J.W. Ochterski, R.L. Martin, K. Morokuma, V.G. Zakrzewski, G.A. Voth, P. Salvador, J.J. Dannenberg, S. Dapprich, A.D. Daniels, O. Farkas, J.B. Foresman, J.V. Ortiz, J. Cioslowski and D.J. Fox, Gaussian Inc., Wallingford CT (2003).

23. H.-Z. Zhou and C.-R. Han, J. Anhui Univ., (Nat. Sci.), 16, 73 (1992).

24. M.E. Squillacote and F. Liang, J. Org. Chem., 70, 6564 (2005).

25. C.W. Bock, Y.N. Panchenko, S.V. Krasnoshchiokov and R. Aroca, J. Mol. Struct., 160, 337 (1987).

26. D. Rowley and H. Steiner, Discuss. Faraday Soc., 10, 198 (1951).

27. A. Contini, S. Leone, S. Menichetti, C. Viglianisi and P. Trimarco, J. Org. Chem., 71, 5507 (2006).

28. Y. Wang, X.-L. Zeng and D.-C. Fang, Acta Chim. Sinica, 68, 941 (2010). 29. R.G. Pearson, J. Chem. Educ., 64, 561 (1987).

30. V. Labet, C. Morell, A. Toro-Labbe and A. Grand, Phys. Chem. Chem. Phys., 12, 4142 (2010).

31. R.G. Pearson, Proc. Natl. Acad. Sci. USA, 83, 8440 (1986). 